\title{
Assessment of a College Orientation Course for International Students
}

\author{
Wilma Fletcher-Anthony and Lampeto Efthymiou
}

International students enter college in the United States with the need to understand the education system in which they study, requirements to maintain their F-1 Visa status, and ways of coping with personal issues. The Counseling Center at Queensborough Community College of the City University of New York offers a free 10-hour course (ST-100) to assist international students as they navigate these challenges. An online assessment of the course was done in spring 2015 with students who had completed the course and were still enrolled at the college. The results showed that students benefitted in their understanding of academic and career requirements, academic integrity, and sexual harassment. In addition, they reported a positive perception of counseling services. Recommendations for improving the course in areas such as understanding college policies and making friends from other countries are discussed.

\section{Introduction}

Orientation programs beyond a single experience are useful for the creation of peer relationships, development of college student identity, and fostering a connection to the college (Soria, Lingren Clark, \& Coffin Koch, 2013). In the case of international students, Olivas and $\mathrm{Li}$ (2006) recommend that these programs address cultural factors and the demands of the U.S. education system and promote campus services. The purpose of the article is to describe a college orientation course for international students and to examine feedback from course participants in order to identify potential changes to content and delivery for improved outcomes.

\section{Review of Literature}

\section{International Students}

Mori (2000), Tas (2013), and Zalaznick (2014) found that international students need support with language, creating connections such as sharing of

Wilma Flecther-Anthony (WFletcherAnthony@qcc.cuny.edu) is the Director of Counseling at Queensborough Community College

Lampeto Efthymiou is the Manager for International Affairs, Immigration \& Study Abroad at Queensborough Community College 
culture, making American friends, creating social relationships and overcoming loneliness, coping with culture shock, and normalizing counseling. These students also need to become familiar with aspects of the American education system, such as advising and mentoring, student-faculty interaction, class participation, office hours, and appropriate ways to communicate (Chen, 1999). Other challenges include coping with parents' expectations of academic achievement, particularly concerning the number of credits and grades (Nilsson, Berkel, Flores, \& Lucas, 2004).

\section{International Student Population at Queensborough Community College}

The Center for International Affairs, Immigration and Study Abroad (CIAISA) at Queensborough Community College (QCC) assists international students with their transition from their home countries to the United States. CIAISA provides immigration guidance, academic advisement and registration services, professional development workshops, and cultural integration opportunities for all its students, which are needed for academic success, professional development, and personal growth.

In March 2015, CIAISA was responsible for reporting and monitoring $184 \mathrm{~F}-1$ visa students representing 39 countries. These students came from Asia (75\%), the Caribbean (8\%), South America (7\%), Africa (3\%), and North America (2\%). The top five countries of origin of these students were China, Korea, Bangladesh, Jamaica, and India. The gender ratio of these students was 104 females to 80 males. Students represented the following age ranges: 18 - 22 (51\%), $23-27$ (35\%), 27 $31(5 \%)$, and 32 and older ( $9 \%)$.

\section{Collaboration Between the Counseling Center and CIAISA}

Introduction to College (ST-100) is an informative and interactive mandatory freshman course designed and taught by licensed mental health professionals in the Counseling Center to introduce all students to QCC. It is partially online (PNET) and lasts for 5 weeks. Each week, there is a face-to-face lesson and an online lesson on Blackboard (QCC's learning management system). Upon the request of CIAISA, the Counseling Center at QCC developed a special section of their Introduction to College Course (ST-100) for international F-1 visa students to promote personal wellness for academic success. The class has zero credits, is free, and does not present an additional educational cost to international students.

Objectives. The modified version of ST-100 is designed to make international students aware of academic expectations, help them to create social cross-cultural relationships with their peers, interact appropriately with faculty and staff, explore career options, and become comfortable seeking counseling services. The course is organized into five modules, which are as follows: 
Week 1: Introductions. In the classroom, students meet in triads and share name, major, country of origin, one interesting fact about their country, and concerns about education and life in the United States. The instructor checks for correct majors, demonstrates the use of Blackboard, reviews the academic calendar, and assigns a library tour for homework that may be done individually or with classmates.

On Blackboard, students learn to navigate essential e-Learning platforms. In addition, they review Title IX resources and answer questions about what they learned and how the guidelines compare with the expectations in their home countries.

Week 2: Communication and Careers. In the classroom, students identify and discuss relationships, diversity, cyberbullying and the use of social media, and harassment. Expectations of the college and professors, including e-mail, academic integrity, and the need for participation, are addressed. For homework, students are asked to review an e-readiness module in Blackboard for appropriate online communication and then send a practice email to the course instructor.

Through Blackboard, students are directed to explore career options using the Focus-2 program, which is an online career counselling tool on the college's career services website. Upon completing the program, students are asked to reflect on their career interests, their family's influence on career choices, and their awareness of the current job market.

Week 3: Time Management and Academic Expectations. In the classroom, students begin to examine personal patterns of behavior that may impact their ability to excel academically.

On Blackboard, students become familiar with their respective programs of study and how to navigate their curriculum requirements. Students also review definitions and explanations of essential college terms.

Week 4: Looking Ahead. Students create specific, measureable, and realistic long-term and short-term goals, and identify potential challenges and resources. In triads, they share study strategies that support their academic goals. The instructor reiterates what students need to know about grading, retention standards, withdrawal policies, and the minimum number of credits and GPA to remain in F-1 Visa status.

On Blackboard, students explore transfer options and use the Student Advisement Degree Audit to find individualized placement results in preparation for their meeting with their academic advisor.

Week 5: Personal Wellness. Students identify and examine stressors in their lives, especially in their role as international students. In small groups, students create and share lists of sources of stress and ways of coping. They explore the impact of these stressors on their academic performance, as well as on their physical and emotional wellbeing. Students will become knowledgeable about mental health issues, including coping strategies to manage daily stressors and life events; on- and off-campus support services; ethical and legal requirements of mental health professionals, including confidentiality; the benefits of seeking services; and the importance of prevention and early intervention. 
On Blackboard, students view the course summary, complete and pass a departmental exit exam, and print out their exam results. Students then bring their results to CIAISA to schedule an appointment for advisement and registration for the following semester.

Course Evaluation: Spring 2015. In order to evaluate the efficacy of the course, which had been offered for the past six semesters, the instructor created and distributed a survey consisting of 17 Likert scale questions and four open-ended questions. The questions assessed students' understanding of the course content and elicited feedback on the impact that the course had on their experience at the college.

CIAISA contacted a pool of 180 international students-all of whom were enrolled at QCC at the time and had previously completed ST-100-via e-mail to inform them that they would soon be receiving an e-mail with a survey from their ST-100 professor. This email from the instructor included an invitation to participate in the survey, as well as a link to the survey, which was hosted by Survey Monkey. The invitation included language indicating to students that their use of the survey link implied consent. The instructor monitored the survey response rate, sent a reminder after two weeks, and closed the survey after six weeks. Ultimately, the survey yielded 47 (26\%) responses.

\section{Results}

\section{Strengths of the Course}

The assessment indicated that the course was most effective in helping students to learn about their goals, degree requirements and career options, academic integrity, and the sexual harassment (Title IX) policy. Students reported they participated frequently in their ST-100 and other required classes. They also reported high intent of utilization of the counseling center, with $62 \%$ reporting that they would be willing to go to the counseling center for help with personal problems.

This finding differs from previous reports of international students' negative feelings toward counseling and the underutilization of college counseling centers (Crockett \& Hays, 2011; Mitchell, Greenwood, \& Guglielmi, 2007; Nilsson, Berkel, Flores, \& Lucas, 2004; Yakushko, Davidson, \& Sanford-Martens, 2008). The positive feelings reported in this survey could be a function of the course's innovative approaches, including collaboration between college counseling centers and international student services, designation of a counselor for international students, direct counselor contact with international students, and the provision of counselor-led groups specifically for international students (Crockett \& Hays, 2011; Komiya \& Eells, 2001; Mori, 2000; Yi, Lin, \& Kishimoto, 2003). 
Survey questions with the least positive response pertain to making friends from other countries in the orientation class, the withdrawal process for international students, and retention standards. The low number of students who identified with the statement, "I made friends from other countries in my ST-100 class," may be attributed to the high percentage of international students coming from the same geographic region-75\% of the program's students come from Asian countries. According to Rientes, Alcott, and Jindal-Snape (2014), when students self-select group members, they tend to select persons who are similar to themselves, thereby limiting intercultural communication. This effect can be alleviated by the instructor creating groups instead of promoting students' selfselection of group members.

Results related to college polices, such as the withdrawal process, indicate that select policies require more attention and in-class discussion. Tidwell and Hanassab (2007) recommended that orientation programs be used to explain policies, protocols, and procedures.

\section{Conclusions and Limitations}

This assessment was done with students who had completed the course over a 2-year period, and the results may be impacted by the time between course completion and data collection. Secondly, the course was taught in a community college that is a part of a large urban university system. The effectiveness of the course may be different in residential campuses or with students attending baccalaureate or graduate degree-granting institutions.

Changes to course content and delivery based on the results of the survey were implemented in fall 2015. In order to assess the efficacy of these changes, the survey will be repeated in spring 2018 with students who completed the course anytime between fall 2015 and fall 2017. At that time, questions will be included regarding students' actual utilization of the Counseling Center in addition to willingness to access counseling services.

\section{References}

Chen, C. P. (1999). Common stressors among international college students: Research and counseling implications. Journal of College Counseling, 2, 49-65.

Crockett, S. A. \& Hays, D. G. (2011). Understanding and responding to the career counseling needs of international college students on U.S. campuses. Journal of College Counseling, 14, 65-79.

Komiya, N. \& Eells, G. T. (2001). Predictors of attitudes towards seeking counseling among international students. Journal of College Counseling, 4, 153-160.

Mitchell, S. L., Greenwood, A. K., \& Guglielmi, M. C. (2007). Utilization of counseling services: Comparing international and US college students. Journal 
of College Counseling, 10, 117-129.

Mori, S. C. (2000). Addressing the mental health concerns of international students. Journal of Counseling and Development, 78, 137-144

Nilsson, J. E., Berkel, L. A., Flores, L. Y., \& Lucas, M. S. (2004). Utilization rate and presenting concerns of international students at a university counseling center: Implications for outreach programming. Journal of College Student Psychotherapy, 19(2), 49-59.

Olivas, M. \& Li, C. (2006). Understanding stressors of international students in higher education. Journal of Instructional Psychology, 33(3), 217-222.

Rientes, B., Alcott, P., \& Jindal-Snape, D. (2014). To let students self-select or not: That is the question for teachers of culturally diverse groups. Journal of Studies in International Education, 18(1) 64-83.

Soria, K. M., Lingren Clark, B., \& Coffin Koch, L. (2013). Investigating the academic and social benefits of extended new student orientations for first-year students. The Journal of College Orientation and Transition, 20(2), 33-45.

Tas, M. (2013). International students: Challenges of adjustment to university life in the US International Journal of Education, 5(3), 1-10.

Tidwell, R. \& Hanassab, S. (2007). New challenges for professional counselors: The higher education international student population. Counselling Psychology Quarterly, 20(4), 313-324.

Yakushko, O., Davidson, M. M., \& Sanford-Martens, T. C. (2008). Seeking help in a foreign land: International students' use patterns for a US university counseling center. Journal of College Counseling, 11, 6-18.

Yi, J. K., Lin, J, G. \& Kishimoto, Y. (2003). Utilization of counseling services by international students. Journal of Instructional Psychology, 30(4), 333-342.

Zalaznick, M. (2014, September). On-boarding internationals: Helping students overcome five top adjustment challenges. University Business, 46-48. 